\title{
ERYTHEMA NODOSUM LEPROSUM
}

\author{
Dr. A. R. DAvison \\ Westfort Institution, Pretoric
}

Erythema nodosum leprosum, hereinafter called ENL, was studied in its relation to duration of treatment and the bacterial index. This paper carries the study further on cases originally reviewed by Davison and Kooij, 1957', and also by Doull and others ${ }^{2-3}$ in 1954 and 1957.

1. An analysis was made by grouping the first series of 201 patients according to the occurence of ENL or not, high or low bacterial index (B.l.), and the period in months required to attain bacterial negativity. There were 101 patients with high B.I., with values varying between $3 \frac{1}{2}$ and 18 , and an average of 8 . Those who escaped ENL were 20, and they took 64 months to reach negativity; whereas the 81 who had ENL took 75 months and more to attain negativity, and there were five still positive at $83,83,87,120$, and 80 months respectively. There were 100 patients with low B.I., with values ranging between $\frac{1}{2}$ and $3 \frac{1}{2}$, and an average of $1 \frac{1}{2}$. Of these, 24 who had no ENL took 57 months to attain negativity, whereas 76 who had ENL took 65 months or more, and one of them took 110 months.

The above analysis took place in June, 1958, on patients who had begun treatment under the Clinical Evaluation Project in February, 19522, but many had been on DDS for various periods before this.

The longer period before positivity and the persistent negativity stand out in patients who had ENL in the high B.I. group. There were four deaths in the ENL group and none in the other group. The time taken to reach negativity between low and high B.I. groups (57 and 64 months respectively) suggests that the initial degree of positivity is important in prognosis. The general conclusion is that ENL is of bad prognostic significance, and more time is taken in the high B.I. group than the low.

2. An analysis was made by grouping cases according to long or short duration of treatment.

In 98 patients with a long duration of treatment (average of 79 months) there were 85 with ENL and 13 without it. In the former, 79 months were required to reach negativity, and in the latter, 77 months. Of the 98 patients, 49 had an average high B.I. of nine, and 49 had an average low B.I. of three.

In 97 patients with a short duration of treatment (average of 56 months), there were 66 who had ENL and 31 who did not. The former took 58 months to become negative, and the latter 53 . The average group B.I. was 3.3, varying from 1 to $5 \frac{1}{2}$.

The analysis showed that long duration of treatment does increase the number developing ENL, and patients with lower B.I. developed less ENL and required shorter treatment.

3. An analysis was now made of a second series of 103 patients as at June, 1958, who had been included in the evaluation project ${ }^{3}$ ) 
in September, 1953, but most of them had been under DDS for various periods before this.

There were 53 patients of high B.I., with values varying between 8 and 25, and an average of 15 . There were 14 who escaped ENL and 39 with it. In the former, the period before negativity was 54 months, but five remained positive at $61,72,68,59$, and 66 months respectively. For 39 with ENL, the period before negativity was also 54 months, but 15 remained positive at $61,72,64,59,66,70,59,76,59$, $65,65,73,74,77$, and 73 months respectively. There were 50 patients with a low B.I., with values ranging from $\frac{1}{2}$ to $7 \frac{1}{2}$, and an average of three. Of these there were 19 without ENL and 31 with it. The former took 41 months to attain negativity, and there was one case still positive at 73 months: the latter took 63 months, and one was still positive at 60 months.

The bad significance of ENL is again shown. There is a prolongation of the time needed to reach negativity, and in one section there is a striking preponderance of cases who still remain positive after 54 months. Whether the initial B.I. is high or low does not seem of much significance.

4. Another analysis of ENL was made on the basis of long treatment or short.

In 40 patients with long treatment, namely an average of 70 months, there were 33 who had ENL and seven who did not. The 33 who had ENL took 70 months to attain negativity and the seven took 69 months. The initial B.I. was between 2 and $10 \frac{1}{2}$, with an average of six for the group.

In 41 patients with short treatment of an average of 43 months, there were 21 who had ENL and 20 who did not. The former took 45 months to attain negativity and the latter took 40 months. The initial B.I. was between 3 and 13, with an average of seven for the group.

It seems that long duration of treatment does increase the number developing ENL. There was no significance in the initial B.I.

\section{Summary}

From analyses of the records of patients who had been used in clinical evaluation studies with J. A. Doull, it appears that ENL is of bad prognostic significance so far as length of treatment is concerned. There were two series of patients. From the first it is clear that the longer the treatment the more ENL develops, and the lower the initial B.I. the less ENL develops and the shorter the treatment required. From both series it appears that ENL does not depend on the degree of positivity but does depend on the duration of treatment.

\section{References}

1. Davison, A. R. and Koois, R. Is Erythema Nodosum Leprosum a Favourable Occurrence? Internat. J. of Leprosy, 25, 1957, 91-98.

2. Doull, J. A. Clinical Evaluation Studies in Lepromatous Leprosy, First Series. Internat. J. of Leprosy, 22, 1954, 377-402.

3. Doull, J. A. Clinical Evaluation Studies in Leprosy, Second Series. Internat. J. of Leprosy, 25, 1957, 173-192. 